\title{
Ocorrência de Trypanosoma evansi em eqüinos no município de Cruz Alta, RS, Brasil
}

\author{
Occurrence of Trypanosoma evansi in equines in Cruz Alta, RS, Brazil
}

\author{
Régis Adriel Zanette ${ }^{\mathrm{I}}$ Aleksandro Schafer da Silva ${ }^{\mathrm{I}}$ Marcio Machado da Costa ${ }^{\mathrm{I}}$ \\ Silvia Gonzalez Monteiro ${ }^{\mathrm{II}^{*}}$ Janio Morais Santurio ${ }^{\mathrm{II}}$ Sonia Terezinha dos Anjos Lopes ${ }^{\mathrm{III}}$
}

- NOTA-

\section{RESUMO}

O objetivo deste trabalho foi relatar a ocorrência de Trypanosoma evansi em eqüinos no município de Cruz Alta, Estado do Rio Grande do Sul, abordando aspectos epidemiológicos e sinais clínicos da infecção. A tripanosomose ocorreu em uma propriedade rural no município de Cruz Alta. Ao exame clínico, observou-se que quatro dos animais apresentavam marcha oscilante, com incoordenação dos membros posteriores. No entanto, eles estavam em bom estado nutricional, sem febre, bem hidratados e alimentavam-se normalmente. Foram coletadas amostras de sangue das éguas para hemograma, sendo identificado aumento das proteínas plasmáticas, leucocitose, eosinofilia e linfocitose em animais com sinais clínicos. No esfregaço sangüíneo periférico, observou-se a forma flagelada do T. evansi em três dos eqüinos.

Palavras-chave: Trypanosoma evansi, surra, eqüinos.

\section{ABSTRACT}

This study aimed at describing the occurrence of Trypanosoma evansi in equines from the city of Cruz Alta, RS, Brazil, relating epidemiological aspects and clinical signs of the infection. The tripanosomiasis occurred in a rural area of Cruz Alta, RS. Clinical signs presented by four animals were stiff and incoordinated gait of the pelvic members, although they were in good nutritional status, without fever, well-hydrated and eating normally. Blood samples were collected from the mares for hemogram. Increased levels of plasmatic proteins, leukocytosis, eosinophilia, and limphocytosis were observed in animals with clinical signs. Flagellated forms of T. evansi were observed in the blood smear of three animals.

Key words: Trypanosoma evansi, surra, equines.
Trypanosoma evansi é um protozoário da seção salivaria, causador da doença secularmente conhecida como mal de cadeiras em eqüinos no Pantanal Mato-grossense (SILVA et al., 2002). Este parasita apresenta distribuição geográfica ampla, mas causa doença significativa em animais de áreas de clima tropical, especialmente África e América Latina (LUN \& DESSER, 1995).

Os tripanosomas patogênicos de importância pecuária estão localizados na seção salivaria, dos quais apenas Trypanosoma vivax, Trypanosoma equiperdum e Trypanosoma evansi podem ser encontrados na América do Sul. O T. vivax é o responsável pela tripanosomose, principalmente em bovinos e outros ruminantes, podendo afetar a saúde e produtividade destes (SILVA et al., 2002).

T. evansi pode ser transmitido mecanicamente por insetos hematófagos das famílias Tabanidae e Muscidae e por morcegos hematófagos (Desmodus rotundus) (HOARE, 1972). Adoença causa sinais clínicos em cavalos, tais como anemia, edema de pernas e partes baixas, letargia, perda de apetite, emagrecimento, febre intermitente, lacrimejamento, aborto (SILVA et al., 1995b, 1995c), e, ocasionalmente, hemorragias na câmara anterior do olho (LOSOS, 1980). A anemia é de natureza hemolítica em resultado da eritrofagocitose no baço, no fígado, nos pulmões, nos nódulos linfáticos, na medula óssea e na circulação sangüínea (JAIN, 1993).

\footnotetext{
ICurso de Medicina Veterinária, Universidade Federal de Santa Maria (UFSM), Santa Maria, RS, Brasil.

"Departamento de Microbiologia e Parasitologia, Centro de Ciências da Saúde (CCS), UFSM, Campus Universitário, Camobi, Km 9, Prédio 20, sala 4232, 97105-900, Santa Maria, RS, Brasil. E-mail: sgmonteiro@uol.com.br. *Autor para correspondência. II'Departamento de Clínica de Pequenos Animais, Centro de Ciências Rurais (CCR), UFSM, Santa Maria, RS, Brasil.
} 
Nos estádios crônicos, os animais tornamse fracos, as membranas mucosas encontram-se pálidas, alguns ictéricos, com nódulos linfáticos superficiais intumescidos e apresentam incoordenação motora com paralisia dos membros posteriores (MONZON et al., 1991). MAHMOUD \& GRAY (1980) descrevem que a doença é rapidamente fatal em cães, eqüinos e camelos.

Nas regiões subtropicais da Argentina, o T. evansi apresenta ocorrência endêmica (MONZON et al., 1990). No Brasil, afeta principalmente eqüinos e a prevalência da infecção varia de região para região (DÁVILA \& SILVA, 2000; HERRERA et al., 2004). A doença é enzoótica em eqüinos do Pantanal Matogrossense (SILVA et al., 1995a), sendo também descrita em cães (NUNES et al., 1994; SILVA et al., 1995b; HERRERA et al., 2004), capivaras (Hydrochaeris hydrochaeris) (NUNES et al., 1993; HERRERA et al., 2004), quatis (Nasua nasua) (NUNES \& OSHIRO, 1990), bovinos, búfalos, pequenos marsupiais e tatus (Dasypus spp.) (HERRERA et al., 2004). FRANKE et al. (1994), ao estudarem a ocorrência de T. evansi na subregião do Pantanal de Poconé, no Estado do Mato Grosso, detectaram a prevalência do parasito em $14 \%$ das capivaras e em 18,6\% dos cães examinados. Segundo estes autores, devido ao contato próximo com cavalos, os cães podem assumir um papel relevante como reservatório na região, assim como capivaras, quatis, marsupiais e tatus. O objetivo deste trabalho foi relatar a ocorrência de T. evansi em eqüinos no município de Cruz Alta, Estado do Rio Grande do Sul, abordando aspectos epidemiológicos e sinais clínicos da infecção.

O surto de tripanosomose ocorreu em janeiro de 2007 em uma criação com 13 eqüinos no município de Cruz Alta, sendo oito éguas adultas, onde cinco delas estavam a amamentar. Segundo o proprietário, quatro das fêmeas apresentavam marcha oscilante com incoordenação dos posteriores, sinal clínico observado nas últimas semanas. Ao exame clínico, confirmou-se o relato do proprietário, no entanto, os animais encontravam-se em bom estado nutricional, sem febre, bem hidratados e alimentando-se normalmente. Das éguas que apresentaram a sintomatologia, duas delas eram animais que haviam parido há um mês. Os eqüinos estavam alocados em área de mata ciliar com presença de capivaras (Hydrochaeris hydrochaeris). Junto aos eqüinos observou-se a presença de moscas do gênero Stomoxys.

Amostras de sangue das oito éguas foram colhidas da veia jugular e armazenadas em tubos com EDTA-Na (sal sódico do ácido etilenodiaminotetracético) a 10\% para hematologia no laboratório de Análises Clínicas do Hospital Veterinário da Universidade
Federal de Santa Maria. Os parâmetros hematológicos analisados neste trabalho foram: número de hemácias, hematócrito (Hct), volume corpuscular médio (VCM), concentração de hemoglobina (Hb), concentração de hemoglobina corpuscular média (CHCM), proteínas plasmáticas, número de leucócitos totais, linfócitos, neutrófilos segmentados, eosinófilos, basófilos e monócitos. As contagens de hemácias, leucócitos totais e determinação da concentração de hemoglobina foram realizadas em aparelho de contagem celular eletrônico, da marca CELM - mod. CC $530\left(\right.$ Celm $\left.^{\circledR}\right)$. As determinações do volume globular e da contagem diferencial dos leucócitos foram efetuadas de acordo com a técnica descrita por FELDMAN et al. (2000). A interpretação dos resultados foi realizada segundo JAIN (1993).

Durante o exame clínico, realizaram-se esfregaços sangüíneos periféricos das oito éguas e de um potro com um mês de idade, por curiosidade, pois este não apresentava sinais clínicos semelhantes aos observados nas fêmeas. Estes foram corados com Panótico Rápido e posteriormente avaliados em microscópio de luz em aumento de 1000 vezes. Devido à disponibilidade de apenas três ratos (Rattus norvergicus) na visita à propriedade, o sangue de três éguas adultas que apresentavam sinais clínicos de enrijecimento do trem posterior foi inoculado, individualmente, via intra-peritonial nos animais para confirmação do diagnóstico por meio da presença do flagelado na circulação dos roedores. Suspeitou-se do surto de tripanosomose por T. evansi devido a dados epidemiológicos, clínicos e hematológicos, sendo que a confirmação se obteve por meio da presença do parasito em esfregaços sangüíneos.

Neste estudo, a suspeita epidemiológica foi baseada na presença de capivaras (Hydrochaeris hydrochaeris), que permaneciam próximo a aguadas, onde os eqüinos estavam alojados, além da morte de cães infectados com o flagelado na propriedade. Vários trabalhos descrevem capivaras como importantes reservatórios para T. evansi (HOARE, 1972; MORALES et al., 1976; NUNES et al., 1993; FRANKE et al., 1994; MUÑOZ \& CHAVEZ, 2001). Segundo RODRIGUES et al. (2005) e SILVA et al. (2002), surtos em capivaras precedem os surtos em eqüinos, mas isso não foi observado nesse relato, pois, conforme o proprietário, não foram observadas capivaras mortas ou com sintomatologia nervosa e incoordenação motora. Entretanto, não se pode descartar a hipótese destes roedores terem sido a fonte de infecção para os animais. A presença da área de mata ciliar e das temperaturas mais elevadas no verão contribui para o grande número de insetos no local, inclusive moscas hematófagas 
Stomoxys e tabanídeos que foram encontrados junto aos eqüinos, sendo esta, uma das formas de transmissão do protozoário entre os animais (RODRIGUES et al., 2005). O carrapato-estrela (Amblyomma cajennense), que parasita capivaras e eqüinos, também atua como vetor da doença (FIGUEIREDO et al., 1999), mas não se constatou a presença deste nos eqüinos. Conforme relatado, um dos cães da propriedade apresentou os sinais clínicos típicos da doença (incoordenação motora, edema de membro posterior, anorexia, perda de peso), morrendo posteriormente. A tripanosomose do mesmo foi comprovada por meio de esfregaço sanguíneo, pela presença do protozoário. Sinais clínicos semelhantes foram descritos em eqüinos (SILVA et al., 1995a) e em cães (AQUINO et al., 1999) infectados por T. evansi. Segundo FRANKE et al. (1994), bovinos e cães podem ser reservatórios eficientes devido ao estreito contato com os eqüinos, podendo participar na transmissão para os mesmos.

Dos quatro animais com alterações hematológicas significativas, em apenas três deles foi observado um aumento das proteínas plasmáticas, já o outro animal apresentava leucocitose, eosinofilia e linfocitose, mas sem alterações nas proteínas plasmáticas. Conforme THOMAS (2000), as infecções por T. evansi estão associadas à alta produção de g globulinas, refletindo em aumento na mensuração das proteínas plasmáticas totais. A linfocitose parece ser um dos achados hematológicos mais importantes em eqüinos com tripanosomose por T. evansi (SILVA et al., 1995a,b; RODRIGUES et al., 2005), fato bastante documentado na tripanosomose de bovinos por $\boldsymbol{T}$. theileri (JAIN, 1986).

Não foi evidenciada anemia no eritrograma dos animais, diferindo de RODRIGUES et al. (2005), que encontrou graus variados de anemia em 17 dos 18 eqüinos infectados naturalmente por T. evansi. A patogênese da anemia em animais infectados por $\boldsymbol{T}$. evansi não é completamente esclarecida, o que pode justificar a ausência neste estudo (SILVA et al., 1995a; MARQUES et al., 2000; AQUINO et al., 2002), mas é sugerido um processo hemolítico (ANOSA \& KANEKO, 1983; JENKINS \& FACER, 1985) provavelmente relacionado à destruição dos eritrócitos pelo sistema imune (JENKINS \& FACER, 1985).

Os quatro animais com alterações hematológicas apresentavam dificuldade de locomoção do trem posterior que, segundo CARREIRA (2005), é típica da doença. Conforme MONZON et al. (1991), esta incoordenação motora com paralisia dos posteriores se dá nos estádios crônicos da infecção.
Nos esfregaços de sangue periférico, realizados em nove animais, observou-se a forma tripomastigota do T. evansi em três dos eqüinos, sendo duas fêmeas que apresentavam sinal clínico e um potro, que não apresentava sinal clínico por razões desconhecidas. Após 10 dias da inoculação do sangue nos ratos, um dos roedores que recebeu sangue de uma das éguas com esfregaço sanguíneo positivo apresentou a forma flagelada na circulação, confirmando-se o diagnóstico de tripanosomose.

O presente relato tem a finalidade de ressaltar a importância da enfermidade no Estado do Rio Grande do Sul, pois, segundo RODRIGUES et al. (2005), mais de 100 eqüinos morreram em surtos ocorridos nesta região. Até 2005 acreditava-se que o homem era refratário ao T. evansi, no entanto, foi relatado na Índia o primeiro caso em humanos (JOSHI et al., 2005). A partir de então, essa doença assumiu caráter zoonótico, tornando-se assim um problema de saúde pública. Com base nos resultados apresentados, conclui-se que a tripanosomose por T. evansi está cada vez mais presente no Rio Grande do Sul, tornando-se um problema para os pecuaristas. Sugere-se que o aumento de casos da doença esteja relacionado à presença de animais silvestres, como capivaras, quatis e demais roedores próximos dos animais com sinais clínicos.

\section{REFERÊNCIAS}

ANOSA, V.O.; KANEKO, J.J. Pathogenesis of Trypanosoma brucei infection in deer mice (Peromyscus maniculatus): Hematologic, erythrocyte biochemical, and iron metabolic aspects. American Journal of Veterinary Research, v.44, p.639-644, 1983.

AQUINO, L.P.C.T. et al. Clinical, parasitological and immunological aspects of experimental infection with Trypanosoma evansi in dogs. Memórias do Instituto Oswaldo Cruz, v.94, p.255-260, 1999.

AQUINO, L.P.C.T. et al. Hematological, biochemical and anatomopathological aspects of the experimental infection with Trypanosoma evansi in dogs. Arquivo Brasileiro de Medicina Veterinária e Zootecnia, v.54, p.8-18, 2002.

CARREIRA, J.C. Sanguessugas podem transmitir o mal de cadeiras, doença de eqüinos que tem grande importância econômica no Brasil. Capturado em $22 \mathrm{dez}$. 2005. Online. Disponível na Internet: http://www.fiocruz.br/ ccs/novidades/abr05/toxo plasmose_fer.htm.

DÁVILA, A.M.R.; SILVA, R.A.M.S. Animal trypanosomiasis in South America. Current status, partnership, and information technology. Annals of the New York Academy of Sciences, v.916, p.199-212, 2000.

FELDMAN, B.F. et al. Veterinary hematology. Philadelphia: Lippincot, 2000. 1344p. 
FIGUEIREDO, L.T.M. et al. Report on ticks collected in the Southeast and Mid-West regions of Brazil: analyzing the potential transmission of tick-borne pathogens to man. Revista da Sociedade Brasileira de Medicina Tropical, v.32, p.613-619, 1999.

FRANKE, C.R. et al. Investigations on naturally occurring Trypanosoma evansi infections in horses, cattle, dogs and capybaras (Hydrochaeris hydrochaeris) in Pantanal de Poconé (Mato Grosso, Brazil). Acta Tropica, v.58, p.159-169, 1994.

HERRERA, H.M. et al. Enzootiology of Trypanosoma evansi in Pantanal, Brazil. Veterinary Parasitology, v.125, p.263275, 2004.

HOARE, C.A. The Trypanosomes of mammals: a zoological monograph. Oxford: Blackwell, 1972. 749p.

JAIN, N.C. Schalm's veterinary hematology. Philadelphia: Lea \& Febiger, 1986. 1921p.

JAIN, N.C. Hemolytic anemias associated with some infectious agents. Essentials of veterinary hematology. Philadelphia: Lea \& Febiger, 1993. Cap.10, p.177-192.

JENKINS, G.C.; FACER C.A. Hematology of African trypanosomiasis. In: TIZARD I. (Ed.). Immunology and pathogenesis of trypanosomiasis. Boca Raton: CRC, 1985. 237p

JOSHI, P.P. et al. Human trypanosomosis caused by Trypanosoma evansi in India: the first case report. American Journal of Tropical Medicine and Hygiene, v.3, p.491495, 2005.

LOSOS, G.J. Diseases caused by Trypanosoma evansi, a review. Veterinary Research Communications, v.4, p.165-181, 1980.

LUN, Z.R.; DESSER, S.S. Is the broad range of hosts and geographical distribuition of Trypanosoma evansi attributable to the loss of maxicircle kinetoplast DNA? Parasitology Today, v.11, p.131-133, 1995.

MAHMOUD, M.M.; GRAY, A.R. Trypanosomiasis due to Trypanosoma evansi (Steel, 1985) Balbiani, 1888; A Review of Recent Research. Tropical Animal Health and Production, v.12, p.35-47, 1980.

MARQUES, L.C. et al. Experimental infection with Trypanosoma evansi in horses: clinical and haematological observations. Revista Brasileira de Parasitologia Veterinária, v.9, p.11-15, 2000.

MONZON, C.M. et al. Comparison between six parasitological methods for diagnosis of Trypanosoma evansi in the subtropical area of Argentina. Veterinary Parasitology, v.36, p.141146, 1990.
MONZON, C.M. et al. Estudios hematologicos en cobayos y equinos infectados con el Trypanosoma evansi (Steel 1885). Veterinaria Argentina, v.8, n.80, p.668-676, 1991.

MORALES, G.A. et al. The capybara (Hydrochaeris hydrochaeris) as a reservoir host for Trypanosoma evansi. Journal of Wildlife Diseases, v.12, p.572-574, 1976.

MUÑOZ, K.; CHÁVEZ, A. Trypanosoma evansi isolated from capibara (Hydrochaeris hydrochaeris). Memórias do Instituto Oswaldo Cruz, v.96, p.945-946, 2001.

NUNES, V.L.B.; OSHIRO, E.T. Trypanosoma (Trypanozoon) evansi in the coati from the pantanal region of the Mato Grosso do Sul State, Brazil. Transactions of the Royal Society of Tropical Medicine and Hygiene, v.84, p.692, 1990.

NUNES, V.L.B. et. al. Investigação epidemiológica sobre Trypanosoma (Trypanozoon) evansi no Pantanal Sul-MatoGrossense. Estudo de reservatórios. Revista Brasileira de Parasitologia Veterinária, v.2, p.41-44, 1993.

NUNES, V.L.B. et. al. Estudos epidemiológicos sobre leishmaniose tegumentar (LT) e Mal das Cadeiras no município de Corguinho, Mato Grosso do Sul - Estudo de reservatórios, 1992-1994. Revista Brasileira de Parasitologia Veterinária, v.3, p.29-35, 1994.

RODRIGUES, A. et al. Outbreaks of Trypanosomiasis in horses by Trypanosoma evansi in the state of Rio Grande do Sul, Brazil: epidemiological, clinical, hematological, and pathological aspects. Pesquisa Veterinária Brasileira, v.25, n.4, p.239249, 2005

SILVA, R.A.M.S. et al. Outbreak of trypanosomosis due to Trypanosoma evansi in horses of Pantanal Mato-grossense. Brazilian Veterinary Parasitology, v.60, p.167-171, 1995a.

SILVA, R.A.M.S. et al. Pathogenesis of Trypanosoma evansi infection in dogs and horses: hematological and clinical aspects. Ciência Rural, v.25, p.233-238, 1995b.

SILVA, R.A.M.S. et al. Trypanosomosis outbreaks due to Trypanosoma evansi in the Pantanal: a preliminary approach on risk factors. Revue D’Élevage et de Médicine Véterinaire dês Pays Tropicaux, v.4, p.315-319, 1995c.

SILVA, R.A.M.S. et al. Trypanosoma evansi e Trypanosoma vivax - Biologia, Diagnóstico e Controle. Embrapa, 2002. Capturado em 12 dez. 2006. Online. Disponível na Internet:http://www.embrapa.com.

THOMAS, J.S. Overview of plasma proteins. In: FELDMAN, B.F. et al. Schalm's veterinary hematology. Philadelphia: Lippincott, 2000. Cap.134, p.891-898. 